University of Nebraska - Lincoln

DigitalCommons@University of Nebraska - Lincoln

P. F. (Paul Frazer) Williams Publications

Electrical \& Computer Engineering, Department

May 1987

\title{
Influence of photodetachment on the switching characteristics of diffuse discharges containing oxygen
}

\author{
G. Schaefer \\ Polytechnic University, Farmingdale, NY \\ G. Z. Hutcheson \\ Mission Research Corporation, Albuquerque, NM \\ K. H. Schoenbach \\ Old Dominion University, Norfolk, VA \\ P. F. Williams \\ University of Nebraska - Lincoln, pfw@moi.unl.edu
}

Follow this and additional works at: https://digitalcommons.unl.edu/elecengwilliams

Part of the Electrical and Computer Engineering Commons

Schaefer, G.; Hutcheson, G. Z.; Schoenbach, K. H.; and Williams, P. F., "Influence of photodetachment on the switching characteristics of diffuse discharges containing oxygen" (1987). P. F. (Paul Frazer) Williams Publications. 4.

https://digitalcommons.unl.edu/elecengwilliams/4

This Article is brought to you for free and open access by the Electrical \& Computer Engineering, Department of at DigitalCommons@University of Nebraska - Lincoln. It has been accepted for inclusion in P. F. (Paul Frazer) Williams Publications by an authorized administrator of DigitalCommons@University of Nebraska - Lincoln. 


\title{
Influence of photodetachment on the switching characteristics of diffuse discharges containing oxygen
}

\author{
G. Schaefer, G. Z. Hutcheson, K. H. Schoenbach, and P. F. WMiams $^{\text {i }}$ \\ Department of Electrical Engineering/Computep Science, Fexas Tech University, Lubbock, \\ Texas 79409.4439
}

(Received 5 January 1987 ; accepted for publication $10 \mathrm{M}$ arch 1987)

\begin{abstract}
Externally sustained discharges can be used as opening and closing switches in pulsed power systems. Admixtures of atachers allow rapid opening when the cxtermal sustaining source is terminateí; however, they will increase losses in the closing phase. Bhotodetachnent has been proposed as an additional control mechanism to overcome these losses. This letter presents measurements on photoionization sustained discharges in argon and nitroger containing admixtures of oxygen uncer the infuence of laser radigtion. Strong changes of the voltagecurrent characteristics have been observed. The infuence of parameters such as percentage of $\mathrm{O}_{2}$, laser power, laser pulse widh, anc eircuit impedance is presented. Additionally, it is shown that photodetachment can enhance the stability of difuse discharges.
\end{abstract}

Extemally sustained difuse discharges can be used as opening and closing switches in pulsed power systems. To achieve short opening times with electron densities the range $n_{e} \leqslant 10^{14} \mathrm{~cm}^{-3}$ electron attachers have to be used. Attachers with high attachment rates at high values of reduced fieid strength $E / N$ and low attachment rates at low values of $E / N$ will allow fast opening when the electron beam is turned of and iow losses in the conduction phase. ${ }^{1,2}$ Such attachers, however, increase the closing time and in crease the loss during switch closure, especially if closure has to be performed in a high impedance system. This efect has been demonstrated in calculations ${ }^{3}$ on discharges in $\mathrm{N}_{2}$ containing $\mathrm{N}_{2} \mathrm{O}$ and in experinents ${ }^{4}$ on discharges in $\mathrm{Ar}$ containing $C_{2} F_{6}$.

It has been proposed that photodetachment can be used to overcome these losses during closure. ${ }^{3,5}$ The infucnce of photodetachment will mainly infuence the discharge characteristics in an intemediate $E / N$ range. Ar low values of $E / N$, attachment will not dominate the discharge if the attacher ased has the properties as mentioned above. At high values of $E / N$-above sel-breakdown-ionization through the discharge electrons will dominate." For applications as a repetitive closing and opening switch the dischatge therefore has to be operated at low values of $E / N$ not infuenced by attachnent in the conduction phase, and at intermediate values of $E / N$ well below self-breakdown and subsequently dominated by attachment in the nonconducting phase, and the transitions between these two phases. The intuence of photodetachment can subsequenty be demonstrated by measuring the current density $(J)$ versus reduced field strength $(E / N)$ characteristics under the infuence of photodetachment.

\footnotetext{
: Present address; Department of Electrical Engineering, Polytechnic University, Farmingdale, NY 11735

b) Present address: Mission Research Corporation, 1720 Randoiph Road, SE, Albuquerçue, NM 87106.

") Tesent address: Department of Electrical Enginetring, Old Dominion University, Nortok, VA 23508.

d) Wresent adiress: Department of Electrical Engineering, University of $\mathrm{Ne}$ braska-Lincohn, Lincoln, NF 68588-05II.
}

The experimental setup ${ }^{7}$ used for our experiments is shown in Fig. 1. The major component is the discharge chamber with a transverse laser electrode configuration (variable gap distance, $d=3.5-10 \mathrm{~mm}$, active electrode width $w=20 \mathrm{~mm}$, electrode length $l=200 \mathrm{~mm}$ ). The electrodes of this chamber are connected to a $125 . \$ 1$ line which is charged to a voltage below self-breakdown of the discharge gap. A resistor in series is used to vary the system impedance. A spark array altraviolet (UV) light source is iocated behind a sereen in one of the main clectrodes. This UV source can produce light pulses with 5 ns rise time and nearly constant emission over several 100 ns. When the UV source is fired, an externally sustained discharge will be initiated in the discharge chamber. Current and voltage probes in the main line allow the evaluation of the time dapendence of current, voltage, and impedance of the discharge. Side windows at the discharge chamber allow the illumination of the discharge volume with a flashlamp pumped dye laser. This iaser produces pulses of anproximately $1000 \mathrm{~ns}$ length and nearly constant power of $\sim 1 \mathrm{NW}$ over the central $400 \mathrm{~ns}$ at $590 \mathrm{~nm}$. With a Pockels cell chopper, short puises of $50 \mathrm{~ns}$

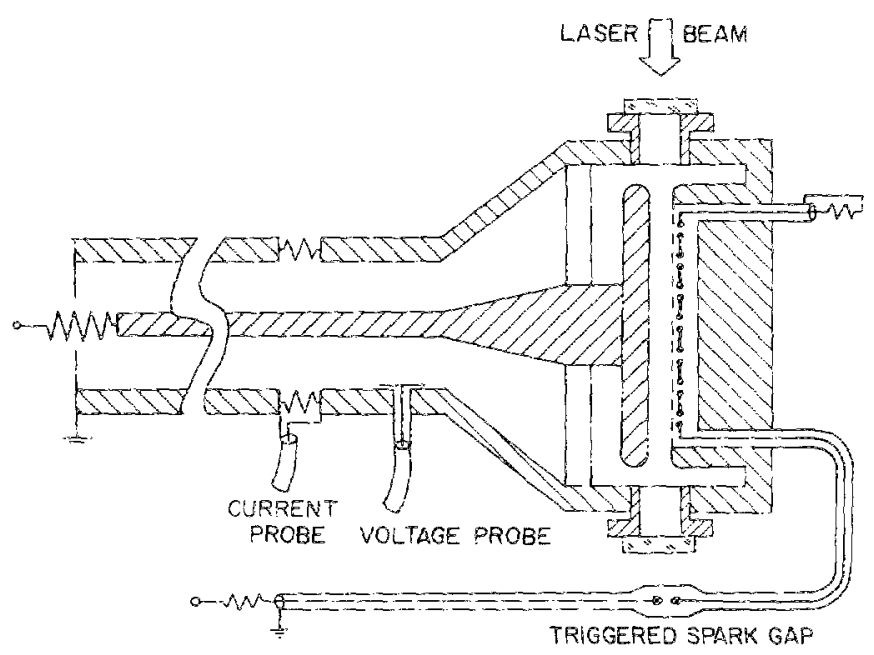

FlG. 1. Experimental setup for UV-sustained, photodetachment-controlled discharge. 


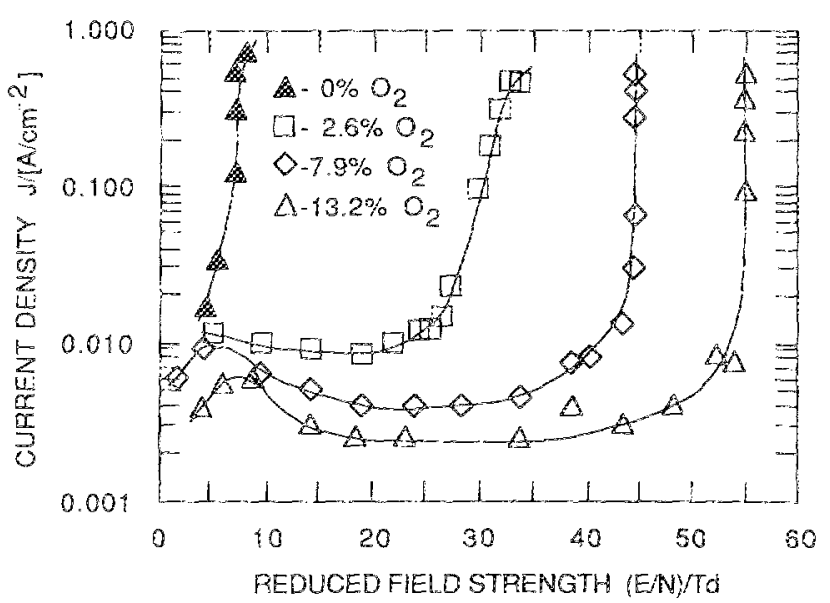

FIG. 2.J-E/N characteristics of UV-sustained and UV-initiated discharges for several concentrations of $\mathrm{O}_{2}$ with $2.6 \% \mathrm{~N}_{2}, 350$ ppm dimenthlaniline, and balance of Ar at $1 \mathrm{~atm}$.

Jengti and $\sim 500 \mathrm{~kW}$ power cen be obtained. The time-dependent measurements of current and voltage across the discharge, with and whthout laser, allow the evaluation of the influence of photodetachment on the $J-E / N$ characteristics and on the transient behavior of the discharge.

Measurements were performed in mixtures of argon and nitrogen with an admixture of oxygen as the attacher. Attachers producing $\mathrm{O}^{-}$as the dominant negative ion are good candidates for photodetachment experiments, since $O$ has a relatively high photodetachment cross section" for photons of approxmately $2 \mathrm{eV}$. The mixture of $\mathrm{Ar}$ and $\mathrm{N}_{2}$ optimizes the ionization efficiency of the UV source. Nitrogen increases the UV yield of the spark sources ${ }^{9}$ while the admixture of Ar increases the pentetration depth of the ionizing padiation. The honization efficiency was further enhanced by using $N, N$ dimethylaniline as an additive with a low ionization potential. ${ }^{\text {ti }}$

The first set of experiments was performed to evaluate the infuence of attachment on the steady-state $J-E / N$ characteristic of the discharge. For these experiments the system

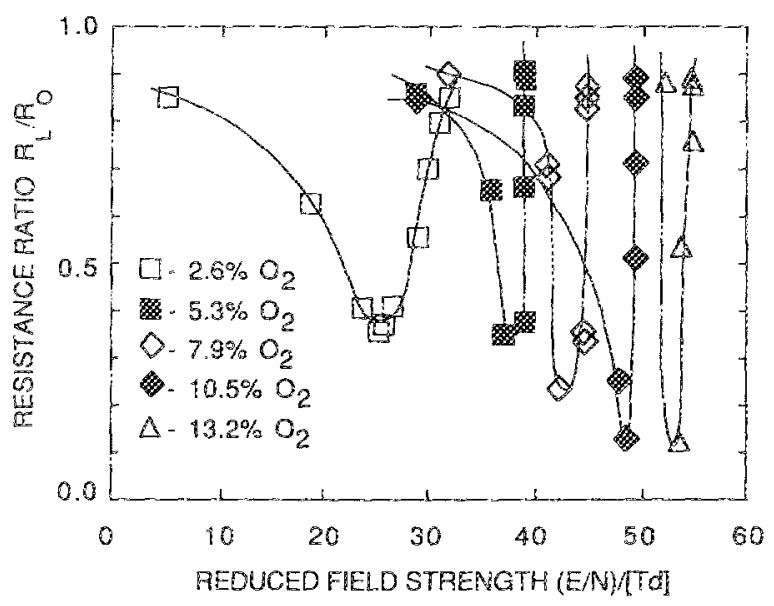

FIG. 3. Infuence of the laser on the discharge resistance $R_{L} / R_{1}$, where $R_{L}$ is the resistance with laser illumination and $R_{0}$ is the resistance withesut laser illumination vs $E / N$ for 125-s system impedance. Gas mixtures coninined various concentrations of $\mathrm{O}, 2.6 \% \mathrm{N3}, 350 \mathrm{ppm}$ dimethylaniline, and balance of $A r$ at 1 atm.

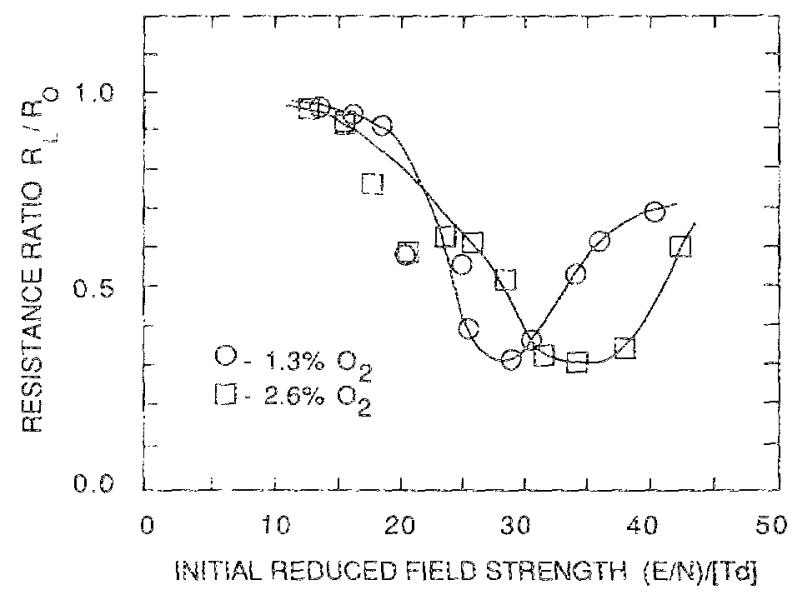

FiG. 4. Bniluence of the laser on the discharge resistances $R_{f} / R_{0}$, where $R_{L}$ is the discharge resistance wh laser ilhumbation and $R_{0}$ is the disCharge resistance without laser Whmination vinital $E / N$ for $13-k 2$ system impedance Gas mixure contained varying concentrations of $0_{2}, 2.6 \% \mathrm{~N}$, 350 ppm dimethylaniline, and balance of Ar at $1 \mathrm{~atm}$.

inpedance was kept small compared to the impodance of the discharge (with nearly constant discharge voltage). One set of data was taken without the laser. Figure 2 shows the $J$ $E / N$ characteristics for gases with varying concentrations of $\mathrm{O}_{2}$. The mixurures used with higher $\mathrm{O}_{2}$ concentrations generated regions of negative differencial conductivity in intermediate $E / N$ ranges of the characteristics. This effect is the consequence of an attachment coefficient that strongly increases with $E / N$. Ar high values of $E / N$ the currents increased drastically. In this $E / N$ range interna ionization through discharge electrons becones signifcant and, therefore, represents the transition to sell-sustained discharges.

Figure 3 shows the influence of photodetachment for varying concentrations of $\mathrm{O}_{2}$ in a low impedance circuit (constant $E / N$ ). For these experiments, the UV source was triggered at the peak power of the $1000 \mathrm{~ns}$ laser pulse. The laser power density in the discharge chamber was $8 \times 10^{5}$ $W / \mathrm{cm}^{2}$. Discharges that did not contain oxygen showed no change in resistance when illuminated by the laser. No infuence of the laser on the discharge characteristics was observed in the low $E / N$ range where no dissociative attachraent occurs. The infuence of the laser starts in the range where the current density reaches a minimum. In this $E / N$ range attachment is strong and the density of negative ions is

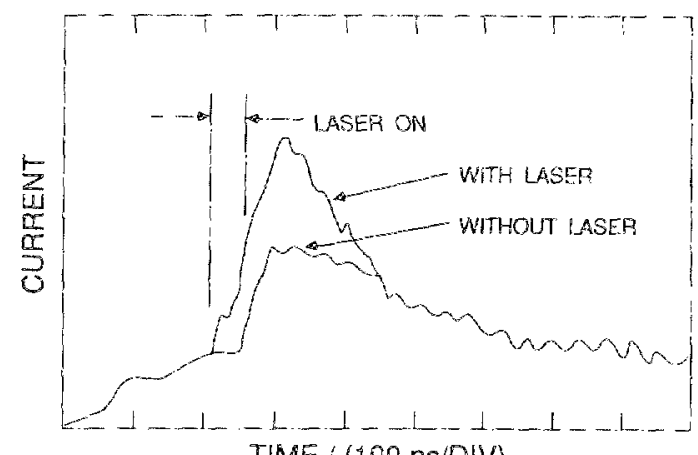

FIG. 5. Current vs time with and without short laser pulse for a gas composition of $13.2 \% \mathrm{O}_{2}, 2.6 \% \mathrm{~N}_{2}, 84.2 \% \mathrm{Ar}$, and $350 \mathrm{ppm}$ dimethylanitine at 1 $\mathrm{atm}$ initial $E / N=50.2 \mathrm{Td}$, and a laser power density $\simeq 400 \mathrm{~kW} / \mathrm{cm}^{2}$. 
nigh. The strongest changes were observed in the transition regime to the self-sustained discharges. Thcreased electron density, due to internal ionization, along with the higher $E / N$ caused a high density of negative ions. Also, the higher oxygen concentrations produced a more pronounced change in resistance, as a result of the higher negative ion densities.

The dependence of the resistance change on the laser intensiry was also measured and was found to be linear up to the maximum intensity of our $1 a \mathrm{ser}, 8 \times 10^{5} \mathrm{~W} / \mathrm{cm}^{2}$. This resuit indicated that only a fraction of the negative ions were being photodetached, and, that with higher laser powers, stronger resistance cinanges could have been attained. ${ }^{5}$

Further experiments involved determining the effect of photodetachment in a high impedance circuit. A $13-k g$ resistor was placed in series with the transmission tine of the diffuse discharge circuit. In such a circuit the increase of current is associated with a decrease of $E / N$ and, consequently, a reduction of the attachment rate. The effect of the laser is therefore expected to be smaller. The laser was operated again in the long pulse mode, and the UV source was triggered at the time of peak laser power. The results are shown in Fig. 4. The abscissa shows the value of $E / N$ just before triggering of the UV source (i.e., the initial $E / N$ ). As in the low impedance measurements, the strongest changes in resistances occurred in the transition regime from externally to self-sustained discharges.

Schafer ef al. ${ }^{3}$ have demonstrated through simulations that short laser pulses occurring soon after discharge initiation can strongly aller the $\mathcal{I}-E / N$ characteristics of the discharge for the remainder of the discharge puise. Figure 5 shows similar results in our experment in which the laser pulse was only on for $\sim 50$ ns soon after discharge initiation. Current density changes caused by short laser pulses occurring later in the discharge were smaller and more ciosely followed the laser in time.

As a final demonstration of the influence of photodetachment, laser enhanced stability experiments were perFormed in the $125-\Omega$ system in a mixture of Ar with $5.3 \% \mathrm{O}_{2}$ and 350 ppm dimethylaniline at 1 atm. Sudden voltage collapse and current changes in the discharges indicated formation of ares. As in the previous experiments, the laser was used with a peak intensity of approximately $8 \times 10^{5} \mathrm{~W} / \mathrm{cm}^{2}$. In five out of five cases where the discharges were not illuminated by the dye haser, arc development cccurred anywhere from 350 ns to $1 \mu$ s after discharge iniviation as previously demonstrated by Norris and Smith. "However, for five out of five cases where the discharges were illuminated, no arcs were observed. By increasing the electron density ${ }^{12}$ and lowering the effective attachment rate, photodetachment enhances discharge stability.
The experiments presented demonstrate that externally sustained discharges in mixtures of $\mathrm{A} F$ and $\mathrm{N}_{2}$ containing admixiures of $\mathrm{O}_{2}$ exhibit a negative diferential conductivity in an intermediate $E / N$ range. This effect is bolieved to be the conseguence of the atrachment coefficient for the dissociative process ( $e+\mathrm{O}_{2} \rightarrow \mathrm{O}^{-}+\mathrm{O}$ ), increasing strongly with $F / N$. Photodetachment with a visible laser can be used to significantly change the discharge characteristics. Resistance changes at moderate laser powers $\left(800 \mathrm{~kW} / \mathrm{cm}^{2}\right)$ were stronges (factor of 8 ) in the $E / N$ range where the ratio of the negative ion density to the eiectron density is highest. This $E / N$ range corresponds to the regime just below the transition from externally sustained to self-sustained, which is the $E / N$ range close to the initial $E / N$ values that would be used for a difuse discharge swith in a high impedance system. Short laser pulses during discharge initiation are sufficient to change the behavior of the entire discharge pulse.

From these experiments, we believe that discharges can be operated as opening switches with low loss in high impedance, burst mode systems, if phorodetachment is utilized Guring discharge initiation. For both switches and lasers, photodetachment can be used as a mechanism to improve the stability of difuse discharges.

The authors would like to thank R. A. Korzekwas for his assistance in the preparation of this letter. This work was jointly supporied by the Air Force Offee of Scientific Research and the Army Research Office under contract AFOSR 84-0032 and by the National Science Foundation under grant No. ECS-8318122.

'K. H. Schoesbach, G. Schacter, M. Kristiansen, I. T. Hatfeld, and A. Hi. Guenther, IEEE Trans. Plasma Sci.

'I. I. Christophourou, \$. R. Inuter, I. A. Carter, and R. A. Mathis, Appl. Phys. Lett. \& 147 (1982).

G. Schater, K. H. Schoenbach, H. Krompholz, M. Kristiansen, and A. K. Guenther, Lascr and Particle Beams 2, 273 (1984).

${ }^{4}$ G. Schaefer, K. F. Schoentegch, M. Kristiansen, B. F. Strickland, R. A. Rorzekwa, and G. Z. Hutcheson, Appl. Phys. Lett. 48, 1776 (1986).

'G. Schaefer, $Y$. F. Williams, K. H. Schoenbach, and J. Moseley, IEEE Trans. Plasma Sci. PS-13, 263 (1983).

(R. T. VanErunt and M. Misakian, J. Appl. Phys. 54, 3074 (1983).

${ }^{\prime} R$. Cooper, G. Hutcheson, M. Kristiansen, G. Schacfer, K. H. Schoenbach, and A. H. Guenther, Proc 4 th IEEE bit. Pulsed Power Conf., IEEE Catalog No. 83CH 1908-3, 726, Albuquercie, NM, 1983.

"E. M. Branscomb, S. I. Smith, and (G. Tisune, J. Chem. Phys. 43, 2906 (1965).

I. J. J. Seguin, D. McKen, and J. 'Tulip, J. Appl. Phys. 28, 487 (1976).

10D. F. Grosien and P. Bletzinger, IEEE J. Quantum Flectron. 22E-13,898 (1977).

"B. Norris and A. L. S. Smith, J. Phys. D 10, L237 (1977).

'R. A. Haas, in Applied Atomic Collision Physics, Volume 3-Gas Lasers, edited by F. W. McDaniel and W. 1. Nighan (Academic, New Ycrk, 1982), p. 423 . 